\title{
Systematic Syntheses and Characterization of Dodecadien-1-ols with Conjugated Double Bond, Lepidopterous Sex Pheromones
}

\author{
Tetsu Ando, Yuichi Kurotsu, Mieko KaIYA \\ and Masaaki UCHIYAMA \\ Department of Plant Protection, Faculty of Agriculture, \\ Tokyo University of Agriculture and Technology, \\ Fuchu, Tokyo 183, Japan
}

Received July 17, 1984

\begin{abstract}
Four geometrical isomers of 5,7-, 6,8-, 7,9- and 8,10-dodecadien-1-ols were systematically synthesized by two routes. One involved the Wittig reaction between $(E)$-2-alkenal and a phosphorane with an appropriate carbon chain, and yielded a mixture of $(E, Z)$ - and $(E, E)$ isomers in a ratio of $c a .3: 2$. The other route comprised of the Wittig reaction of a 2-alkynal and the stereoselective reduction of the triple bond to a $(Z)$-double bond via hydroboration with dicyclohexylborane to give a mixture of $(Z, Z)$ - and $(Z, E)$-isomers in a ratio of $6: 1 \sim 10: 1$. Both the mixtures were separately chromatographed on a silica gel column impregnated with silver nitrate to give four geometrically pure isomers. With 9,11-diene they were analysed by GC on a capillary column, HPLC, silver nitrate impregnated TLC, and ${ }^{13} \mathrm{C}$ NMR.
\end{abstract}

Since 1974 we have been widely screening monoene compounds in several fields and successfully discovered attractants for about two hundred lepidopterous species. ${ }^{1,2)}$ The increasing identification of diene type sex pheromones from female moths encouraged us to conduct systematical syntheses and field tests on the diene compounds in order to get more information on the sex pheromones of native Lepidoptera. Among the dienes, dodecadienic compounds with a conjugated double bond are one of the most fascinating groups, because some isomers have already been identified as the components of the sex pheromones of pest insects as follows; $(5 Z, 7 E)$-5,7-dodecadien-1ol for Dendrolimus spectabilis, ${ }^{3)}$ Dendrolimus punctatus $^{4)}$ and Malacosoma disstria, ${ }^{5}$ (5Z,7E)-5,7-dodecadienyl acetate for $D$. punctatus, ${ }^{4)}(5 Z, 7 E)$-5,7-dodecadienal for $M$. disstria $^{5)}$ and Dendrolimus pini, ${ }^{6)}(5 E, 7 Z)$ 5,7-dodecadienal for Malacosoma californicum, ${ }^{7)}$ (7E,9Z)-7,9-dodecadienyl acetate for Lobesia botrana, ${ }^{8)}$ (8E, 10E)-8,10-dodecadien1-ol for Cydia pomonella, ${ }^{9)}(8 E, 10 E)-8,10$ - dodecadienyl acetate for Cydia nigricana, ${ }^{10)}$ Hedya nubiferana ${ }^{11)}$ and Rhyacionia rigidana, ${ }^{12)}$ and (E)-9,11-dodecadienyl acetate for Diparopsis castanea, ${ }^{13)}$ Sparganothis directana $^{14)}$ and Rhyacionia frustrana. ${ }^{15)}$

In this paper we wish to present a synthetic procedure for all the geometrical isomers of 5,7-, 6,8-, 7,9-, 8,10- and 9,11-dodecadien-1-ols with their chromatographic characters and ${ }^{13} \mathrm{C}$ NMR results. The results of analyses of these isomers by MS will be reported separately and field attraction tests are now under way.

\section{Syntheses}

It was not so easy to synthesize separately each of the four geometrical isomers in the stereoselective mode, so we examined synthetic routes in which only one of two $\mathrm{C}=\mathrm{C}$ double bonds was furnished highly stereoselectively and the other by a Wittig reaction rather nonspecifically. Separation of each component from the mixture of the four geometrical isomers with a conjugated diene system must be difficult. We, however, expect that the two 


$$
\begin{aligned}
& \mathrm{HO} \cdot\left(\mathrm{CH}_{2}\right)_{m} \cdot \mathrm{OH} \underset{\text { Dihydropyran }}{/ \mathrm{H}^{+}} \mathrm{HO} \cdot\left(\mathrm{CH}_{2}\right)_{m} \cdot \mathrm{O}^{\mathrm{THP}} \stackrel{\mathrm{PCC}}{\underset{/ \mathrm{CH}_{2} \mathrm{Cl}_{2}}{\longrightarrow}} \\
& 1 \\
& 2
\end{aligned}
$$
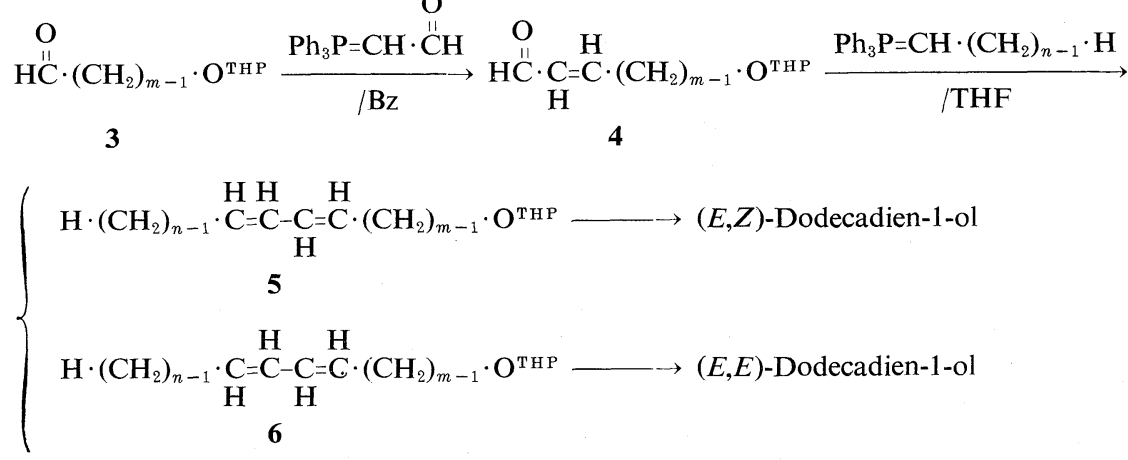

\begin{tabular}{lcccc} 
& $\begin{array}{l}5,7-\text { Diene } \\
m=5, n=5\end{array}$ & $\begin{array}{l}6,8-\text { Diene } \\
m=6, n=4\end{array}$ & $\begin{array}{c}\text { 7,9-Diene } \\
m=7, n=3\end{array}$ & $\begin{array}{c}\text { 8,10-Diene } \\
m=8, n=2\end{array}$ \\
\hline$(E, Z)$-Isomer & 64 & 62 & 61 & 61 \\
$(E, E)$-Isomer & 36 & 38 & 39 & 39 \\
\hline
\end{tabular}

a They were measured by GC with an FFAP capillary column $(25 \mathrm{~m})$ at $140^{\circ} \mathrm{C}$.

SCHEME 1.

isomers can be separated successfully by a chromatographical technique.

Dodecadien-1-ols with $(E, Z)$ - or $(E, E)$ geometry were prepared by the following method (see Scheme 1). The starting materials for 5,7-, 6,8-, 7,9- and 8,10-dodecadien-1-ols were 1,5-pentanediol $(\mathbf{1}, m=5), 1,6$-hexanediol $(1, m=6), 1,7$-heptanediol $(1, m=7)$ and 1,8-octanediol $(\mathbf{1}, m=8)$, respectively. One hydroxyl group of the diols (1) was protected by 2,3-dihydropyrane to obtain mono-THP ethers (2), which were oxidized by pyridinium chlorochromate to aldehydes (3). Coupling reactions of the aldehydes (3) with formylmethylenetriphenylphosphorane ${ }^{16)}$ gave 2-alkenals (4), the $\mathrm{C}=\mathrm{C}$ double bonds of which were revealed to have $(E)$-geometry by the large coupling constant $(c a .16 \mathrm{~Hz})$ between olefinic protons. ${ }^{1} \mathrm{H}$ and ${ }^{13} \mathrm{C}$ NMR analyses showed that the $(E)$-2-alkenals (4) were not contaminated by their corresponding $(Z)$-isomers. For obtaining the chain with twelve carbons, each of the $(E)$-2-alkenals $(4$, $m=5 \sim 8$ ) was coupled with an appropriate phosphorane $(n=5 \sim 2)$ prepared from a corresponding phosphonium salt with $n$ butyllithium in dry THF. The ratios of the two geometrical isomers, $(E, Z)$-isomer (5) and $(E, E)$-isomer (6), were $c a .3: 2$ on NMR without distinction of the chain length of the phosphoranes and the aldehydes (4). The correct ratios shown in the table in Scheme 1 were measured by FFAP capillar GC after removal of the protecting group. Column chromatography using silica gel impregnated with silver nitrate $\left(\mathrm{SiO}_{2}-\mathrm{AgNO}_{3}\right)$ separated each component from the mixture of $(E, Z)$ and $(E, E)$-dodecadien-1-ols.

Syntheses of the $(Z, Z)$ - and $(Z, E)$-isomers of 6,8-, 7,9- and 8,10-dienes occurred also from diols (1, $m=6 \sim 8)$ (see Scheme 2). THP ethers (8) of the bromohydrins (7) obtained by the half bromination of the diols (1) were converted into acetylene compounds $(9, m=6 \sim 8)$ via the coupling reaction with lithium acetylide-ethylenediamine complex in DMSO. ${ }^{17)}$ A compound $(9, m=5)$ was synthesized by the same acetylene coupling reaction 


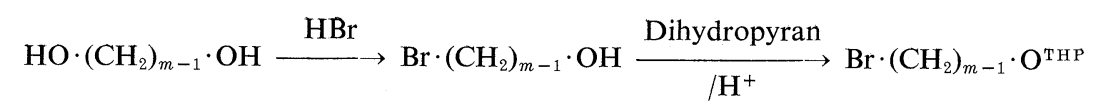

1

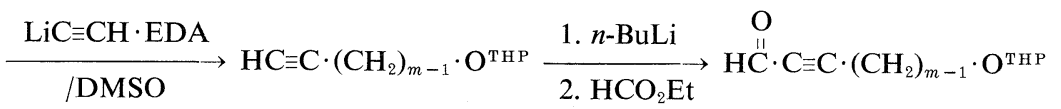

9

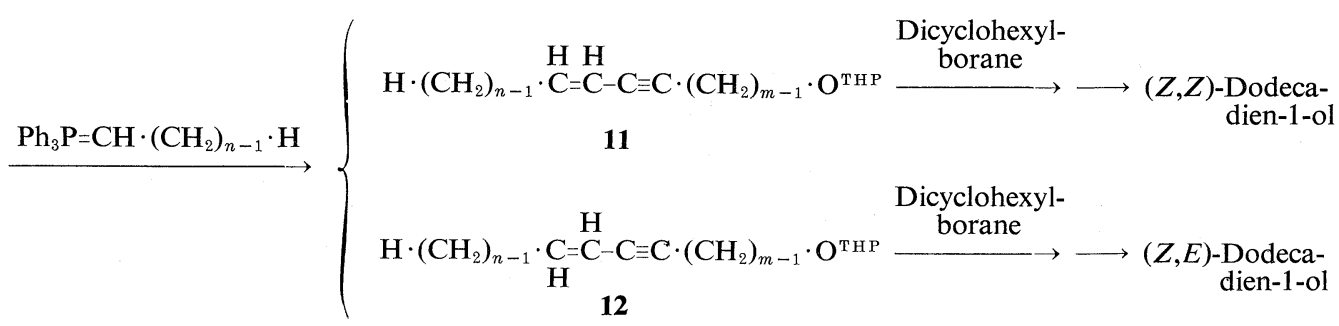

Ratios of $(Z, Z)$-Dodecadien-1-ol and $(Z, E)$-Dodecadien-1-ol ${ }^{a}$

\begin{tabular}{lcccc}
\hline & $\begin{array}{l}5,7-D i e n e \\
m=5, n=5\end{array}$ & $\begin{array}{l}\text { 6,8-Diene } \\
m=6, n=4\end{array}$ & $\begin{array}{l}7,9-D i e n e \\
m=7, n=3\end{array}$ & $\begin{array}{c}8,10 \text {-Diene } \\
m=8, n=2\end{array}$ \\
\hline$(Z, Z)$-Isomer & 91 & 89 & 86 & 86 \\
$(Z, E)$-Isomer & 9 & 11 & 14 & 14 \\
\hline
\end{tabular}

$a$ They were measured by GC with an FFAP capillary column $(25 \mathrm{~m})$ at $140^{\circ} \mathrm{C}$.

SCHEME 2.

of 4-chlorobutan-1-ol THP ether, which was prepared from 4-chlorobutan-1-ol. Formylation of lithium acetylides of the acetylenes $(9, m=5 \sim 8)$ gave 2 -alkynals $(\mathbf{1 0}),{ }^{18)}$ which were coupled with appropriate phosphoranes $(n=5 \sim 2)$ using $n$-butyllithium in dry THF to give enyne compounds (11 and 12) having a twelve carbon straight chain. NMR analyses showed that the $(Z)$-isomers (11) were major products at any double bond positional isomers. Highly selective and specific conversion of the triple bond in the conjugated enyne system into a $(Z)$-double bond was accomplished by hydroboration with dicyclohexylborane and successive protonolysis. After removal of the THP protecting group, $\mathrm{SiO}_{2}-\mathrm{AgNO}_{3}$ column chromatography separated each component from the mixtures of $(Z, Z)$ - and $(Z, E)$-dodecadien-1-ols in the ratios shown in Scheme 2.

(E)-9,11-Dodecadien-1-ol was also prepared by the Wittig reaction between 11tetrahydropyranyloxy-(E)-2-undecenal $m=9$ ) and methyl triphenylphosphonium io- dide followed by the removal of the THP ether. The $(Z)$-isomer of 9,11-dodecadien-1-ol was synthesized by a modification of the method described by Nesbitt et al. ${ }^{19)}$

\section{Chromatography}

On GC analyses of 5,7-, 6,8- and 7,9dodecadien-1-ols with a high polar column (FFAP, $25 \mathrm{~m}$ ), four geometrical isomers were well eluted separately in the following order as shown in Table I; $(Z, E)-,(E, Z)-,(Z, Z)$ - and $(E, E)$-isomers. It is interesting that the $(E, E)$ isomers were last, while the $R t$ value of the $(E)$-isomer of a monoene compound is generally smaller than that of the $(Z)$-isomer. For 8,10-diene compounds, however, the $(E, E)$-isomer was eluted between the $(Z, E)$ and $(E, Z)$-isomers and the order of elution of the four geometrical isomers was different from the above dienes. $R t$ values of the 8,10-dienes were greater than those of the above dienes and separation of the geometrical isomers among the 8,10-dienes was not so sufficient as for the other dienes. Two geometrical isomers 
Table I. GC $R t$ Values (min) of Dodecadien-1-ols on an FFAP Capillary Column $(25 \mathrm{~m})$ at $140^{\circ} \mathrm{C}^{a}$

\begin{tabular}{cccccc}
\hline & $5,7-$ Diene & 6,8 -Diene & 7,9-Diene & 8,10-Diene & 9,11-Diene \\
\hline$(E, Z)$-Isomer & $14.4^{b}$ & 14.3 & 14.6 & 16.9 & \\
$(Z, E)$-Isomer & $14.0^{b}$ & 13.9 & 14.2 & 15.7 & $13.9^{c}$ \\
$(E, E)$-Isomer & $16.2^{b}$ & 15.7 & 16.0 & 16.5 & $13.9^{d}$ \\
$(Z, Z)$-Isomer & $15.1^{b}$ & 15.0 & 15.3 & 17.1 & 1 \\
\hline
\end{tabular}

a Under this condition, 1-tridecanol and 1-tetradecanol were eluted at $10.5 \mathrm{~min}$ and $15.8 \mathrm{~min}$, respectively.

$b$ A mixture of four geometrical isomers of 5,7-diene shows four well separated peaks.

c Rt of $(E)-9,11$-dodecadien-1-ol.

d $R t$ of (Z)-9,11-dodecadien-1-ol.

Table II. HPlC $R t$ Values (min) of Dodecadien-1-ols on an Nucleosil $5 \mathrm{NO}_{2}$ Column $(8 \mathrm{~mm}$ i.d. $\times 15 \mathrm{~cm})$ WITH $2.5 \%$ 2-PROPANOL IN $n$-HEXANE AT A FLOW RATE OF $1.5 \mathrm{ml} / \mathrm{min}$

\begin{tabular}{cccccc}
\hline & 5,7-Diene & 6,8-Diene & 7,9-Diene & 8,10-Diene & 9,11-Diene \\
\hline$(E, Z)$-Isomer & 11.7 & 11.7 & 11.8 & 12.0 & \\
$(Z, E)$-Isomer & $11.5^{a}$ & 11.4 & 11.6 & 11.8 & \\
$(E, E)$-Isomer & 12.0 & 11.9 & 12.0 & 11.8 & $11.6^{b}$ \\
$(Z, Z)$-Isomer & $12.2^{a}$ & 12.1 & 12.1 & 11.9 & $11.6^{c}$ \\
\hline
\end{tabular}

a A mixture of $(5 Z, 7 E)$ - and $(5 Z, 7 Z)$-isomers shows almost two separated peaks.

${ }^{b} \quad R t$ of $(E)-9,11$-dodecadien-1-ol.

c $R t$ of (Z)-9,11-dodecadien-1-ol.

of 9,11-diene compounds had the same $R t$ values on GC even with this capillary column.

HPLC analyses of all the synthesized dienes were conducted using three kinds of high polar columns (Nucleosil $\mathrm{NO}_{2}, \mathrm{CN}$ and $\mathrm{N}\left(\mathrm{CH}_{3}\right)_{2}$ ) and two solvent systems (2.5\% 2-propanol in $n$-hexane and $15 \%$ THF in $n$-hexane). Among these, the combination of the $\mathrm{NO}_{2}$ column and 2-propanol in $n$-hexane showed the best separation of the geometrical isomers. The $R t$ values under these conditions are listed in Table II. For the 5,7-, 6,8- and 7,9-dienes, $(Z, E)-,(E, Z)-,(E, E)-$ and $(Z, Z)$-isomers were eluted from the $\mathrm{NO}_{2}$ column in that order. The elution order of $(E, E)$ - and $(Z, Z)$ isomers on this HPLC is noteworthily different from that on GC with a FFAP column. For 8,10-diene compounds, the four geometrical isomers were eluted in an order different from that for the other dienes and their $R t$ values were closely similar. Discrimination of the two geometrical isomers of 9,11-diene on HPLC was also impossible.
Isomers with the same geometrical diene system at a different position, the 5,7-, 6,8-, 7,9- or 8,10-position, showed spots with almost the same $R f$ values on a $\mathrm{SiO}_{2}-\mathrm{AgNO}_{3}$ TLC plate. On $\mathrm{SiO}_{2}-\mathrm{AgNO}_{3}$ chromatography, $(E, E)$-isomers revealed the highest mobility of the four geometrical isomers and $(Z, Z)$ isomers the lowest mobility. The mobilities of $(Z, E)$ - and $(E, Z)$-isomers were intermediate and they were indistinguishable from each other. This result is comprehensible, since any $(E)$-isomers of monoene compounds have higher mobilities than the corresponding $(Z)$ isomers. The $R f$ values of the two geometrical isomers of 9,11-diene were unfortunately the same. Comparison of the $R f$ values between conjugated dienes and monoene compounds showed the following; solvent system: $25 \%$ ethyl acetate in benzene, $(E)$-8-dodecen-1-ol: $0.49,(Z)$-isomer: $0.33,(5 E, 7 E)$-5,7-dodecadien-1-ol: $0.41,(5 E, 7 Z)$ - and $(5 Z, 7 E)$-isomers: $0.36,(5 Z, 7 Z)$-isomer: 0.29 , and $(E)$ and $(Z)-9,11$-dodecadien-1-ols: 0.33 . 

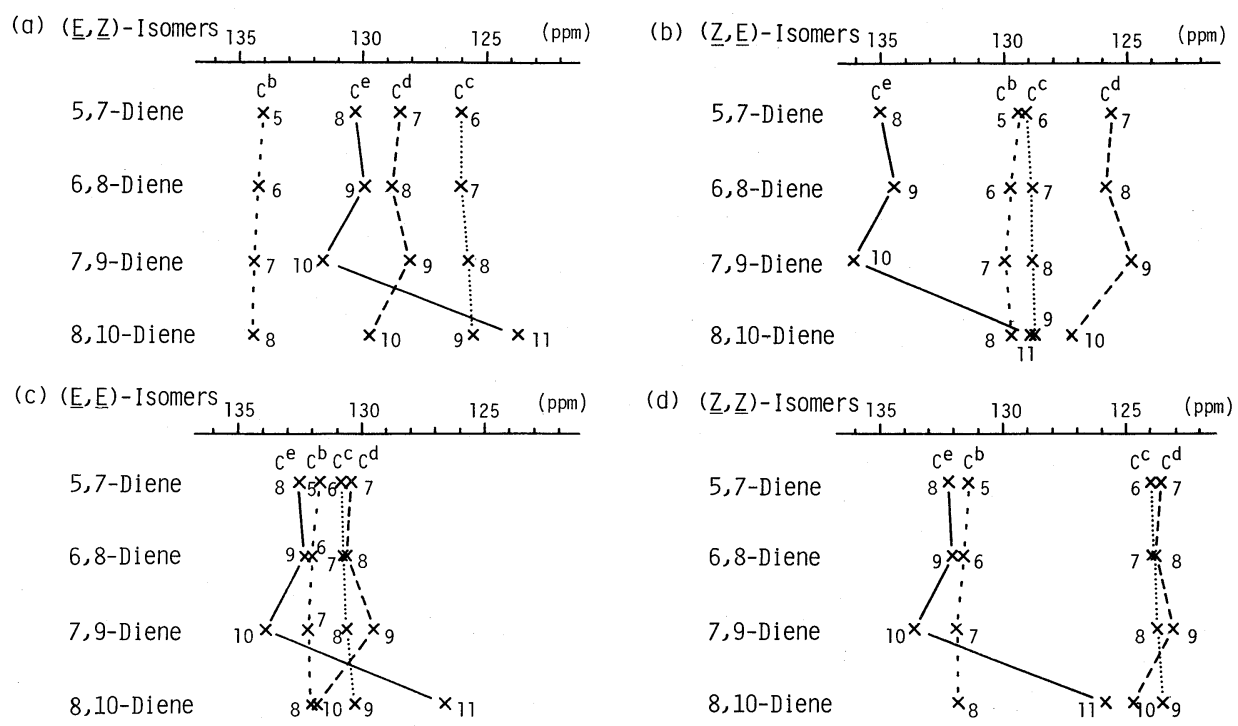

FIG. 1. Comparison between ${ }^{13} \mathrm{C}$ NMR Chemical Shifts (ppm) for the Olefinic Carbons in the Conjugated Diene System $\left(\mathrm{C}^{\mathrm{a}}-\mathrm{C}^{\mathrm{b}}=\mathrm{C}^{\mathrm{c}}-\mathrm{C}^{\mathrm{d}}=\mathrm{C}^{\mathrm{e}}-\mathrm{R}\right)$.

This figure shows the ${ }^{13} \mathrm{C}$ NMR chemical shifts of olefinic carbons, $\mathrm{C}^{\mathrm{b}} \sim \mathrm{C}^{\mathrm{e}}$, in the $\mathrm{C}^{\mathrm{a}}-\mathrm{C}^{\mathrm{b}}=\mathrm{C}^{\mathrm{c}}-\mathrm{C}^{\mathrm{d}}=\mathrm{C}^{\mathrm{e}}-\mathrm{R}$ conjugated diene system, namely $C^{5} \sim C^{8}$ in 5,7-diene, $C^{6} \sim C^{9}$ in 6,8-diene, $C^{7} \sim C^{10}$ in 7,9-diene and $C^{8} \sim C^{11}$ in 8,10-diene. Signals of $(E, Z)$-isomers (a) and $(Z, E)$-isomers (b) were assigned by $\left\{{ }^{13} \mathrm{C}\right\}-{ }^{1} \mathrm{H}$ selective decoupling and those of $(E, E)$-isomers (c) and $(Z, Z)$-isomers (b) by an empirical rule. Chemical shift differences are induced by changes of the chain length of the $\mathrm{R}$ group attached to $C^{\mathrm{e}}$, such as methyl $(8,10$ diene), ethyl (7,9-diene), propyl (6,8-diene) and butyl (5,7-diene), particularly by the change of the $R$ group from methyl to ethyl.

\section{${ }^{13}$ C NMR Analyses}

We have already proposed tentative ${ }^{13} \mathrm{C}$ NMR assignments for allylic and olefinic carbons of 5,7-, 8,10- and 9,11-dienes from the results of $\left\{{ }^{1} \mathrm{H}\right\}-{ }^{13} \mathrm{C}$ selective decoupling experiments and two empirical rules in the previous paper. ${ }^{20)}$ Now, the empirical rules were confirmed by systematical analyses by ${ }^{13} \mathrm{C}$ NMR of the conjugated dienic compounds including additional 6,8- and 7,9-dienes.

The first rule concerns the substitutional effect of the alkyl chain attached to the terminal of the conjugated diene system. Namely, with the $(E, Z)$ - and $(Z, E)$-isomers, the signals of which could be assigned indisputably by $\left\{{ }^{1} \mathrm{H}\right\}-{ }^{13} \mathrm{C}$ selective decoupling, the chemical shift of each olefinic carbon in the conjugated diene system $\left(\mathrm{C}^{\mathrm{a}}-\mathrm{C}^{\mathrm{b}}=\mathrm{C}^{\mathrm{c}}-\mathrm{C}^{\mathrm{d}}=\right.$ $\mathrm{C}^{\mathrm{e}}-\mathrm{R}$ ) changed according to the length of the alkyl group (R) as shown in Fig. 1-(a) and (b). The patterns in Fig. 1-(a) and (b) are very similar and the same magnitude of the substitutional effect is expected to happen in the cases of $(E, E)$ - and $(Z, Z)$-isomers, too. Based on this supposition, we could find one possibility for ${ }^{13} \mathrm{C}$ chemical shift assignments for the olefinic carbons of $(E, E)$ - and $(Z, Z)$-dienes, as shown in Fig. 1-(c) and (d), respectively.

The second rule concerns the chemical shift changes of allylic and olefinic carbons by converting the geometry of the conjugated diene system. Values of the chemical shift changes obtained for 6,8- and 7,9-dienes were in good agreement with those for 5,7-, 8,10- and 9,11-dienes reported previously. Namely, when the $(E)$-configuration of $\mathrm{a} \mathrm{C}^{\mathrm{b}}=$ $\mathrm{C}^{\mathrm{c}}$ double bond in the $\mathrm{C}^{\mathrm{a}}-\mathrm{C}^{\mathrm{b}}=\mathrm{C}^{\mathrm{c}}-\mathrm{C}^{\mathrm{d}}=\mathrm{C}^{\mathrm{e}}$ diene system is changed to a $(Z)$-configuration without the conversion of the $\mathrm{C}^{\mathrm{d}}=\mathrm{C}^{\mathrm{e}}$ double bond, the signals of $\mathrm{C}^{\mathrm{a}}, \mathrm{C}^{\mathrm{b}}, \mathrm{C}^{\mathrm{c}}$ and $\mathrm{C}^{\mathrm{d}}$ shift upfield by ca. 5, 2.5, 2 and 5 ppm, respectively, and the signal of $\mathrm{C}^{\mathrm{e}}$ downfield by $c a .2 \mathrm{ppm}$, regardless of the geometry of the $\mathrm{C}^{\mathrm{d}}=\mathrm{C}^{\mathrm{e}}$ double bond. 
TABle III. Assignment of ${ }^{13} \mathrm{C}$ MNR Chemical Shifts ${ }^{a}$

\begin{tabular}{|c|c|c|c|c|c|c|c|c|c|c|c|c|}
\hline Compound & $\mathrm{C}^{1}$ & $\mathrm{C}^{2}$ & $\mathrm{C}^{3}$ & $\mathrm{C}^{4}$ & $\mathrm{C}^{5}$ & $\mathrm{C}^{6}$ & $\mathrm{C}^{7}$ & $\mathrm{C}^{8}$ & $\mathrm{C}^{9}$ & $\mathrm{C}^{10}$ & $\mathrm{C}^{11}$ & $C^{12}$ \\
\hline \multicolumn{13}{|l|}{ 5,7-Dodecadien-1-ol } \\
\hline (5E,7Z)-Isomer & 62.6 & 32.3 & 25.6 & 32.6 & 134.0 & 126.0 & 128.5 & 130.3 & 27.4 & 31.9 & 22.3 & 14.0 \\
\hline$(5 Z, 7 E)$-Isomer & 62.8 & 32.4 & 25.9 & 27.4 & 129.4 & 129.1 & 125.6 & 135.0 & 32.6 & 31.6 & 22.3 & 13.9 \\
\hline$(5 E, 7 E)$-Isomer & 62.4 & 32.2 & 25.7 & $32.3^{b}$ & 131.7 & 130.8 & 130.4 & 132.5 & $32.4^{b}$ & 31.6 & 22.3 & 14.0 \\
\hline$(5 Z, 7 Z)$-Isomer & 62.4 & 32.3 & 25.9 & 27.2 & 131.4 & 124.0 & 123.6 & 132.2 & 27.2 & 31.9 & 22.4 & 14.0 \\
\hline \multicolumn{13}{|l|}{ 6,8-Dodecadien-1-ol } \\
\hline$(6 E, 8 Z)$-Isomer & 62.8 & 32.7 & 25.4 & 29.3 & 32.8 & 134.2 & 126.0 & 128.8 & 129.9 & 29.8 & 22.9 & 13.8 \\
\hline$(6 Z, 8 E)$-Isomer & 62.8 & 32.7 & 25.5 & 29.6 & 27.7 & 129.7 & 128.9 & 125.8 & 134.5 & 35.0 & 22.6 & 13.7 \\
\hline$(6 E, 8 E)$-Isomer & 62.8 & 32.7 & 25.4 & 29.3 & 32.6 & 132.0 & 130.7 & 130.6 & 132.3 & 34.7 & 22.6 & 13.7 \\
\hline$(6 Z, 8 Z)$-Isomer & 62.8 & 32.7 & 25.5 & 29.6 & 27.5 & 131.6 & 123.9 & 123.8 & 132.0 & 29.5 & 22.8 & 13.8 \\
\hline \multicolumn{13}{|l|}{ 7,9-Dodecadien-1-ol } \\
\hline (7E,9Z)-Isomer & 62.9 & 32.8 & 25.7 & 29.1 & 29.4 & 32.8 & 134.4 & 125.7 & 128.1 & 131.6 & 21.0 & 14.3 \\
\hline$(7 Z, 9 E)$-Isomer & 62.8 & 32.8 & 25.7 & 29.1 & 29.8 & 27.7 & 129.9 & 128.8 & 124.8 & 136.1 & 25.9 & 13.7 \\
\hline$(7 E, 9 E)$-Isomer & 62.9 & 32.8 & 25.7 & 29.0 & 29.5 & 32.6 & 132.2 & 130.6 & 129.5 & 133.9 & 25.6 & 13.7 \\
\hline$(7 Z, 9 Z)$-Isomer & 62.8 & 32.8 & 25.7 & 29.1 & 29.7 & 27.4 & 131.9 & 123.7 & 123.1 & 133.6 & 20.8 & 14.2 \\
\hline \multicolumn{13}{|l|}{8,10 -Dodecadien-1-ol } \\
\hline$(8 E, 10 Z)$-Isomer & 62.7 & 32.8 & 25.8 & $29.4^{c}$ & $29.4^{c}$ & $29.5^{c}$ & 32.9 & 134.4 & 125.5 & 129.7 & 123.7 & 13.2 \\
\hline$(8 Z, 10 E)$-Isomer & 62.9 & 32.8 & 25.8 & $29.3^{d}$ & $29.4^{d}$ & $29.8^{d}$ & 27.7 & 129.7 & 128.7 & 127.2 & 128.9 & 18.3 \\
\hline$(8 E, 10 E)$-Isomer & 63.0 & 32.8 & 25.7 & $29.2^{e}$ & $29.3^{e}$ & $29.4^{e}$ & 32.5 & 132.0 & 130.3 & 131.8 & 126.6 & 18.0 \\
\hline$(8 Z, 10 Z)$-Isomer & 62.9 & 32.8 & 25.8 & $29.3^{f}$ & $29.4^{f}$ & $29.7^{f}$ & 27.5 & 131.8 & 123.5 & 124.7 & 125.8 & 13.1 \\
\hline \multicolumn{13}{|l|}{ 9.11-Dodecadien-1-ol } \\
\hline$(E)$-Isomer & 62.9 & 32.8 & 25.8 & $29.1^{g}$ & $29.2^{g}$ & $29.4^{g}$ & $29.5^{g}$ & 32.5 & 135.5 & 130.9 & 137.4 & 114.6 \\
\hline (Z)-Isomer & 62.7 & 32.7 & 25.8 & $29.2^{h}$ & $29.4^{h}$ & $29.5^{h}$ & $29.6^{h}$ & 27.7 & 132.9 & 129.2 & 132.3 & 116.6 \\
\hline
\end{tabular}

a Relative values (ppm) from internal TMS in $\mathrm{CDCl}_{3}$ solution.

$b \sim h \quad$ Chemical shift values may be reversed.

The NMR chemical shift proposed for every carbon in dodecadien-1-ols synthesized systematically is shown in Table III. Almost all of them, especially the olefinic carbons, afford sufficiently separated signals. Then ${ }^{13} \mathrm{C}$ NMR measurements of synthetic dienes can be expected to give some clues as to their geometry and purity.

\section{EXPERIMENTAL}

Instruments. GC was performed with a Shimadzu GC4BPF gas chromatograph equipped with a flame ionization detector, an integrator (Chromatopac C-R1B) and a capillary column (FS-WCOT FFAP, $0.25 \mathrm{~mm}$ i.d. $\times$ $25 \mathrm{~m}$ ). The HPLC system consisted of a Jasco twincle pump, a variable loop injector (VL-611) and a variable wavelength UV spectrometer (Uvidec-100-II) operated at $235 \mathrm{~nm}$; the columns used were of Nucleosil $5 \mathrm{NO}_{2}(8 \mathrm{~mm}$ i.d. $\times 15 \mathrm{~cm}), \quad 5 \mathrm{CN}(8 \mathrm{~mm}$ i.d. $\times 20 \mathrm{~cm})$ and $5 \mathrm{~N}\left(\mathrm{CH}_{3}\right)_{2}$ $(8 \mathrm{~mm}$ i.d. $\times 20 \mathrm{~cm})$. They were operated at $1.5 \mathrm{ml} / \mathrm{min}$ for all separations. IR spectra were recorded as thin films with a Jasco IR-G Infrared spectrophotometer. ${ }^{1} \mathrm{H}$ and ${ }^{13} \mathrm{C}$ NMR spectra were measured with a JEOL FX 200 Fourier
Transform NMR spectrometer at 199.50 and $50.10 \mathrm{MHz}$, respectively, under the same conditions as given previously. ${ }^{20)}$

5-Tetrahydropyranyloxypentan-1-ol $(2, m=5) .{ }^{1} \mathrm{H}$ NMR $\delta$ ppm: $1.4 \sim 1.9(12 \mathrm{H}, \mathrm{m}), 3.41$ and $3.76(2 \mathrm{H}, \mathrm{dt} J=10,6$ $\left.\mathrm{C}_{2} \mathrm{O}^{\mathrm{THP}}\right), 3.49$ and $3.85\left(2 \mathrm{H}, \mathrm{m} \mathrm{C}_{2} \mathrm{O}_{-}\right), 3.64(2 \mathrm{H}, \mathrm{t}$ $\left.J=6.5 \quad \underline{\mathrm{H}}_{2} \mathrm{OH}\right), \quad 4.58 \quad(1 \mathrm{H}, \quad \mathrm{t} \quad J=3-\mathrm{OCHO}-) .{ }^{13} \mathrm{C}$ NMR ppm: $C^{1} 62.2, C^{2} 32.5, C^{3} 22.5, C^{4} 29.5, C^{5} 67.5$, THP ether 98.9, 62.4, 30.8, 25.5 and 19.7.

5-Tetrahydropyranyloxypentaral $(3, m=5) .{ }^{1} \mathrm{H}$ NMR $\delta$ ppm: $2.45\left(2 \mathrm{H}, \mathrm{td} J=7,2 \mathrm{CH}_{2} \mathrm{HC}=\mathrm{O}\right), 3.3 \sim 3.9(4 \mathrm{H}, \mathrm{m}$ $\left.\mathrm{CH}_{2} \mathrm{O}-\right), 4.58(1 \mathrm{H}, \mathrm{t} J=3-\mathrm{OCH}-), 9.76(1 \mathrm{H}, \mathrm{t} J=2$ $\underline{\mathrm{HC}}=\mathrm{O}) .{ }^{13} \mathrm{C}$ NMR ppm: $\mathrm{C}^{1} 202.4, \mathrm{C}^{2} 43.6, \mathrm{C}^{3} 19.1, \mathrm{C}^{4}$ 29.2, $C^{5}$ 67.0, THP ether $98.8,62.3,30.7,25.5$ and 19.6.

7-Tetrahydropyranyloxy-(E)-2-heptenal $(\mathbf{4}, m=5)$. A solution of 5-tetrahydropyranyloxypentanal $(3, m=5)$ $(40 \mathrm{mmol}, \quad 7.44 \mathrm{~g})$ and formylmethylenetriphenylphosphorane $^{16)}(100 \mathrm{mmol}, 30.40 \mathrm{~g})$ in dry benzene $(200 \mathrm{ml})$ was refluxed for $40 \mathrm{hr}$. After removal of the solvent, the crude product was extracted with $n$-hexane. IR analysis showed that the crude extract included a small amount of the unreacted aldehyde $\left(1720 \mathrm{~cm}^{-1}\right)$ and the aldehyde $\left(1630 \mathrm{~cm}^{-1}\right)$ coupled with the phosphorane 
twice. By careful separation on a silica gel column, the pure $(E)$-2-heptenal $(\mathbf{4}, m=5)$ was obtained in a $37 \%$ yield. IR $\lambda_{\max } \mathrm{cm}^{-1}: 2900,2850,1680,1130,1110,1070$, 1030. ${ }^{1} \mathrm{H}$ NMR $\delta$ ppm: $2.38\left(2 \mathrm{H}, \quad \mathrm{m} \mathrm{CH} \mathrm{CH}_{2} \mathrm{CH}=\mathrm{CH}\right)$,

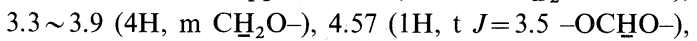
$6.13\left(1 \mathrm{H}\right.$, dd $\left.J=16,7.5 \mathrm{CH}_{2} \mathrm{CH}=\mathrm{CH}\right), 6.87(1 \mathrm{H}, \mathrm{dt} J=$ 16, $\left.7 \mathrm{CH}_{2} \mathrm{CH}=\mathrm{CH}\right), 9.51(1 \mathrm{H}$, d $J=7.5 \mathrm{HC}=\mathrm{O}) .{ }^{13} \mathrm{C}$ NMR ppm: $C^{1} 193.9, C^{2} 133.1, C^{3} 158.4, C^{4} 32.5, C^{5} 24.7$, $\mathrm{C}^{6} 29.2, \mathrm{C}^{7}$ 67.0, THP ether $98.9,62.3,30.7,25.5$ and 19.7 .

(5E, 7Z)- and (5E, 7E)-5,7-Dodecadien-1-ol THP ethers (5 and $6, m=5, n=5$ ). To a suspension of $n$-pentenyltriphenylphosphonium bromide $(11 \mathrm{mmol}, 4.54 \mathrm{~g})$ in dry THF $(60 \mathrm{ml}), n$-butyllithium $(1.8 \mathrm{M} n$-hexane solution, $c a .8 \mathrm{ml}$ ) was added slowly with stirring at $10^{\circ} \mathrm{C}$ under nitrogen until the salt was completely dissolved. After the addition, the reaction mixture was stirred for $30 \mathrm{~min}$, and then the aldehyde $(4, m=5)(10 \mathrm{mmol})$, $2.12 \mathrm{~g}$ ) was added at the same temperature. This mixture was stirred for $2 \mathrm{hr}$, and then poured into ice-water, and extracted with $n$-hexane. After washing with water, $1 \mathrm{~N}$ hydrochloric acid and sodium bicarbonate solution, the extract was dried over anhydrous magnesium sulfate and then concentrated to give a mixture of an $(E, Z)$-isomer (5) and an $(E, E)$-isomer (6) in a $44 \%$ yield.

5-Bromopentan-1-ol $(7, m=6) .{ }^{1} \mathrm{H}$ NMR $\delta \mathrm{ppm}: 3.41$ $\left(2 \mathrm{H}, \mathrm{t} J=6.5 \mathrm{CH}_{2} \mathrm{Br}\right), 3.65\left(2 \mathrm{H}, \mathrm{t} J=6.5 \mathrm{C}_{2} \mathrm{OH}\right) .{ }^{13} \mathrm{C}$ NMR ppm: $C^{1} 62.6, C^{2} 31.9, C^{3} 24.4, C^{4} 32.6, C^{5} 33.6$.

5-Bromopentan-1-ol THP ether $(\mathbf{8}, m=6)$. 1H NMR $\delta$ ppm: $3.3 \sim 3.9\left(4 \mathrm{H}, \mathrm{m} \mathrm{C}_{2} \mathrm{O}-\right), 3.41\left(2 \mathrm{H}, \mathrm{t} J=7 \mathrm{CH}_{2} \mathrm{Br}\right)$, 4.57 (1H, t $J=3$-OC브-). ${ }^{13} \mathrm{C}$ NMR ppm: $\mathrm{C}^{1} 67.2, \mathrm{C}^{2}$ $28.9, \mathrm{C}^{3} 25.0, \mathrm{C}^{4} 32.7, \mathrm{C}^{5} 33.6$, THP ether $98.8,62.3,30.8$, 25.5 and 19.7 .

4-Chlorobutan-1-ol THP ether. ${ }^{1} \mathrm{H}$ NMR $\delta$ ppm: 1.7 $\left(2 \mathrm{H}, \mathrm{m} \mathrm{CH}_{2} \mathrm{CH}_{2} \mathrm{O}-\right), 1.9\left(2 \mathrm{H}, \mathrm{m} \mathrm{CH}_{2} \mathrm{CH}_{2} \mathrm{Cl}\right), 3.58(2 \mathrm{H}, \mathrm{t}$ $\left.J=6.5 \mathrm{CH}_{2} \mathrm{Cl}\right), 3.3 \sim 3.9\left(4 \mathrm{H}, \mathrm{m} \mathrm{CH}_{2} \mathrm{O}-\right) .{ }^{13} \mathrm{C}$ NMR ppm: $\mathrm{C}^{1}$ 66.6, $\mathrm{C}^{2} 27.2, \mathrm{C}^{3} 29.8, \mathrm{C}^{4} 44.9$, THP ether 98.8, 62.3, $30.8,25.6$ and 19.6 .

5-Hexyn-1-ol THP ether $(9, m=5) .{ }^{1} \mathrm{H}$ NMR $\delta \mathrm{ppm}$ : $1.95(1 \mathrm{H}, \mathrm{t} J=2.5 \underline{\mathrm{HC}} \equiv \mathrm{C}), 2.22(2 \mathrm{H}, \mathrm{td} J=6.5,2.5$ $\left.\mathrm{C}_{2} \mathrm{C} \equiv \mathrm{C}\right), 3.3 \sim 3.9\left(4 \mathrm{H}, \mathrm{m} \mathrm{C} \underline{\mathrm{H}}_{2} \mathrm{O}-\right), 4.58(1 \mathrm{H}, \mathrm{t} J=$ 3.5 -OCHO-). ${ }^{13} \mathrm{C}$ NMR ppm: $\mathrm{C}^{1} 66.9, \mathrm{C}^{2} 28.9, \mathrm{C}^{3} 25.6$, $\mathrm{C}^{4}$ 18.3, $\mathrm{C}^{5} 84.3, \mathrm{C}^{6}$ 68.4, THP ether $98.8,62.2,30.7$, 25.4 and 19.6 .

7-Tetrahydropyranyloxy-2-heptynal $\quad(10, \quad m=5)$. Formylation of 5-hexyn-1-ol THP ether $(\mathbf{9}, m=5)$ was carried out in the same manner as described in ref. 18. IR $\lambda_{\max } \mathrm{cm}^{-1}: 2925,2650,2275,2220,1660,1130,1115,1070$, 1030. ${ }^{1} \mathrm{H}$ NMR $\delta$ ppm: $2.42\left(2 \mathrm{H}, \mathrm{td} J=7,1 \mathrm{C}_{2} \mathrm{C} \equiv \mathrm{C}\right)$, $3.3 \sim 3.9$ (4H, m C $\left._{2} \mathrm{O}-\right), 4.57$ (1H, t $\left.J=3.5-\mathrm{OC} \underline{\mathrm{HO}}-\right)$, $9.18(1 \mathrm{H}, \mathrm{t} J=1 \mathrm{HC}=\mathrm{O}) .{ }^{13} \mathrm{C}$ NMR ppm: $\mathrm{C}^{1} 177.1, \mathrm{C}^{2}$ $81.8, C^{3} 94.6, C^{4} 19.0, C^{5} 24.6, C^{6} 28.8, C^{7} 66.6$, THP ether
$98.9,62.3,30.7,25.5$ and 19.6.

(Z)- and (E)-7-Dodecen-5-yn-1-ol THP ethers (11 and 12, $m=5, n=5)$. 2-Heptynal $(\mathbf{1 0}, m=5)$ was coupled with $n$-pentenyltriphenylphosphonium bromide using the same procedure as for the Wittig reaction of $4 .{ }^{1} \mathrm{H}$ NMR $\delta \mathrm{ppm}$ : (Z)-isomer, $0.91\left(3 \mathrm{H}, \mathrm{t} J=7 \mathrm{CH}_{3}\right), 2.29(2 \mathrm{H}$, dtd $J=7.5$, $\left.7.5,1 \mathrm{CH}_{2} \mathrm{CH}=\mathrm{CH}\right), 2.38\left(2 \mathrm{H}, \operatorname{td} J=6.5,2 \mathrm{CH}_{2} \mathrm{C} \equiv \mathrm{C}\right)$, $3.3 \sim 3.9\left(4 \mathrm{H}, \mathrm{m} \mathrm{C}_{2} \mathrm{O}-\right), 4.58(1 \mathrm{H}, \mathrm{t} J=3.5-\mathrm{OCHO}-)$, $5.41(1 \mathrm{H}, \mathrm{dtt} J=10.5,2,1 \mathrm{CH}=\mathrm{C} \underline{\mathrm{HC}} \equiv \mathrm{C}), 5.80(1 \mathrm{H}, \mathrm{dt}$ $J=10.5,7.5 \mathrm{CH}=\mathrm{CHC} \equiv \mathrm{C}),(E)$-isomer, $2.07(2 \mathrm{H}, \mathrm{dtd} J=$ $\left.7,7,1 \mathrm{CH}_{2} \mathrm{CH}=\mathrm{CH}\right), 2.32\left(2 \mathrm{H}, \operatorname{td} J=6.5,1.5 \mathrm{CH}_{2} \mathrm{C} \equiv \mathrm{C}\right)$, $5.43(1 \mathrm{H}, \mathrm{dtt} J=16,1.5,1 \mathrm{CH}=\mathrm{CHC} \equiv \mathrm{C}), 6.03(1 \mathrm{H}, \mathrm{dt}$ $J=16,7 \mathrm{CH}=\mathrm{CHC} \equiv \mathrm{C}) .{ }^{13} \mathrm{C}$ NMR ppm: $(Z)$-isomer, $\mathrm{C}^{\mathrm{i}}$ 67.0, C $C^{2} 29.0, C^{3} 25.8, C^{4} 19.4, C^{5}$ 94.0, $C^{6} 77.7, C^{7} 109.4$, $C^{8} 142.5, C^{9} 29.8, C^{10} 31.1, C^{11} 22.3, C^{12} 13.9$, THP ether $98.8,62.2,30.8,25.6$ and 19.6, $(E)$-isomer, $C^{4} 19.2, C^{5}$ 88.2, $C^{6} 79.7, C^{7} 109.9, C^{8} 143.4, C^{9} 32.7, C^{10} 31.1, C^{11}$ 22.2 .

(5Z,7Z)- and (5Z,7E)-Dodecadien-1-ol THP ethers. To a stirred and ice cooled solution of dicyclohexylborane in THF $(20 \mathrm{ml})$, which was prepared from $\mathrm{NaBH}_{4}(6 \mathrm{mmol}$, $0.23 \mathrm{~g}$ ), boron fluoride-ether $(8 \mathrm{mmol}, 1.14 \mathrm{~g})$ and cyclohexene (16 mmol, $1.13 \mathrm{~g})$, a solution of a mixture of $\mathbf{1 1}$ and $12(m=5, n=5)(6 \mathrm{mmol}, 1.57 \mathrm{~g})$ in THF $(20 \mathrm{ml})$ was added dropwise at $0^{\circ} \mathrm{C}$. The reaction mixture was maintained at room temperature for $5 \mathrm{hr}$, diluted with $2 \mathrm{ml}$ of glacial acetic acid, and then heated at $60^{\circ} \mathrm{C}$ for $5 \mathrm{hr}$. Oxidation of the resulting dicyclohexylborinate was achieved with $6 \mathrm{~N}$ sodium hydroxide $(8 \mathrm{ml})$ followed by the dropwise addition of $2 \mathrm{ml}$ of $30 \%$ hydrogen peroxide at $30^{\circ} \mathrm{C}$. The mixture was then stirred for an additional $30 \mathrm{~min}$ before working up. The product was extracted with $n$-hexane and the extract was concentrated in vacuo after the usual work up. The residue was chromatographed on a silica gel column developed with $n$-hexane-benzene and benzene-ethyl acetate solvent systems to give a mixture of $(5 Z, 7 Z)$ - and $(5 Z, 7 E)$-isomers in a $83 \%$ yield.

Acknowledgments. We are grateful to Professor N. Takahashi and Dr. S. Yoshida of the University of Tokyo for their invaluable advice. This work was supported in part by Grants-in-Aid for Scientific Research from the Agricultural Chemical Society of Japan, the graduates' association of Tokyo University of Agriculture and Technology, and the Ministry of Education, Science and Culture of Japan (No. 58760089).

\section{REFERENCES}

1) T. Ando, S. Yoshida, S. Tatsuki and N. Takahashi, Agric. Biol. Chem., 41, 1485 (1977).

2) T. Ando, H. Kuroko, S. Nakagaki, O. Saito, T. Oku and N. Takahashi, Agric. Biol. Chem., 45, 487 (1981).

3) T. Ando, M. H. Vu, S. Yoshida, N. Takahashi, S. Tatsuki, K. Katagiri, A. Yamane, T. Ikeda and S. 
Yamazaki, Agric. Biol. Chem., 46, 709 (1982).

4) K'o Hsueh T'ung Pao, 24, 1004 (1979) (in Chinese).

5) M. D. Chisholm, E. W. Underhill, W. Steck, K. N. Slessor and G. G. Grant, Environ. Entomol., 9, 278 (1980).

6) H. J. Bestmann, K. H. Koschatzky, H. Platz, J. Sü $\beta$, O. Vostrowsky, W. Knauf, G. Burghardt and I. Schneider, Liebigs Ann. Chem., 1359 (1982).

7) E. W. Underhill, M. D. Chisholm and W. Steck, Can. Entomol., 112, 629 (1980).

8) W. L. Roelofs, J. Kochansky, R. Cardé, H. Arn and S. Rauscher, Mitt. Schweizer. Entomol. Gesellschaft, 46, 71 (1973).

9) M. Beroza, B. A. Bierl and H. R. Moffitt, Science, 183, 89 (1974).

10) A. R. Greenway and C. Wall, J. Chem. Ecol., 7, 563 (1981).

11) B. Frerot, E. Priesner and M. Gallois, Z.
Naturforsch., 34c, 1248 (1979).

12) A. S. Hill, C. W. Berisford, U. E. Brady and W. L. Roelofs, Environ. Entomol., 5, 959 (1976).

13) B. F. Nesbitt, P. S. Beevor, R. A. Cole, R. Lester and R. G. Poppi, J. Insect Physiol., 21, 1091 (1975).

14) L. B. Bjostad, E. F. Tashenberg and W. L. Roelofs, J. Chem. Ecol., 6, 487 (1980).

15) A. S. Hill, C. W. Berisford, U. E. Brady and W. L. Roelofs, J. Chem. Ecol., 7, 517 (1981).

16) S. Trippett and D. M. Walker, J. Chem. Soc., 1266 (1961).

17) W. N. Smith and O. F. Beumel, Jr., Synthesis, 441 (1974).

18) H. Hauptmann and M. Mader, Synthesis, 307 (1978).

19) B. F. Nesbitt, P. S. Beevor, R. A. Cole, R. Lester and R. G. Poppi, Tetrahedron Lett., 4669 (1973).

20) T. Ando, K. Kusa, M. Uchiyama, S. Yoshida and N. Takahashi, Agric. Biol. Chem.. 47, 2849 (1983). 